\title{
La comunidad morisca de Ágreda (Soria) a fines del siglo XVI
}

\author{
Enrique Cantera montenegro *
}

\section{INTRODUCCIÓN}

A lo largo de los últimos decenios, y en estrecha conexión con el auge conocido por los estudios sobre minorías étnico-religiosas, la investigación sobre los moriscos españoles ha conocido un importante desarrollo, desde los primeros y muy meritorios trabajos, ya clásicos, de Boronat y Barrachina ${ }^{1}$, Danvila y Collado ${ }^{2}$, Janer ${ }^{3}{ }^{\circ}$ Lea $^{4}$, por citar solamente algunos de los más destacados autores que contribuyeron a la apertura de esta importante línea de investigación historiográfica. En el momento actual, la realidad morisca en la España Moderna es ya bien conocida, y desde unos planteamientos metodológicos renovados, acordes con el progreso de la ciencia histórica ${ }^{5}$.

Por este motivo, pocas noticias realmente novedosas pueden encontrarse en la documentación para el conocimiento del problema morisco en su conjunto. Sin embargo, el estudio de comunidades moriscas concretas, o de una comarca determinada, sigue siendo fundamental para matizar algunas ideas o para cuantificar determinadas realidades.

* UNED. Madrid.

' Boronat y Barrachina, Pascual, Los moriscos españoles y su expulsión. Estudio histórico crítico. Valencia 1901. 2 vols.

2 Danvila y Collado, Manuel, La expulsión de los moriscos españoles. Madrid 1883.

3 JANER, Florencio, Condición social de los moriscos en España, causas de su expulsión y consecuencias que ésta produjo en el orden político y económico. Madrid 1857.

4 LEA, Henry Charles, The moriscos of Spain; their conversion and expu/sion. London 1901.

5 A este respecto, véanse los trabajos de ARiÉ, Rachel, "Les études sur les morisques en Espagne à la lumière des travaux récents", en Revue des Études /slamiques, 1967, págs. 225229; García-ARENAL, Mercedes, "Últimos estudios sobre los moriscos: Estado de la cuestión», en Al-Qantara, IV (1983), págs. 101-114; y BunEs, Miguel Angel de, Los moriscos en el pensamiento histórico. Historiografía de un grupo marginado. Madrid 1983. 
Y en esta línea se encuentra este trabajo en el que, mediante el análisis de unas nóminas de penitenciados reconciliados por el tribunal de la Inquisición de Navarra, se profundiza en el estudio de la comunidad morisca de Ágreda a fines del siglo XVI, aportándose algunas noticias que pueden ser de interés para el mejor conocimiento de la realidad morisca castellana.

Una de estas nóminas consiste en una relación de todos los sambenitos ${ }^{6}$ que en el año 1583 se encontraban expuestos en la Iglesia Colegial de Santa María de la Redonda de Logroño, correspondientes a personas no naturales de esta ciudad. En esta misma nómina se relacionan un total de cuarenta y tres vecinos de Ágreda que fueron penitenciados en distintos autos de fe a lo largo del siglo XVI, y cuyo sambenito había sido renovado o puesto de nuevo en la visita que en el año 1583 hizo a Logroño el inquisidor Gaitán ${ }^{7}$.

De estos cuarenta y tres sambenitos tan sólo siete fueron renovados en la visita del inquisidor Gaitán, y corresponden a personas que fueron penitenciados en los años 1528, 1529, 1532 y 1536: cinco son moriscos y dos judeoconversos. Pero estas siete personas quedan fuera de nuestro estudio, pues pertenecen a una generación anterior a la que aquí se estudia. Los treinta y seis sambenitos restantes corresponden a moriscos vecinos de Ágreda que fueron penitenciados en los autos de fe celebrados los años 1577 (cuatro), 1578 (trece), 1580 (otros trece) y 1583 (seis).

La segunda de las nóminas objeto de este trabajo consiste en una relación de moriscos de Ágreda que fueron reconciliados por el licenciado Fernán Cortés, inquisidor apostólico del reino de Navarra y su partido, como consecuencia del edicto de gracia dado en el año $1588^{8}$. La publicación de un edicto de gracia suponía la apertura de un periodo de perdón general a todas las personas que acudieran por su propia voluntad a confesar y abjurar de sus errores, arrepintiéndose de los mismos. Esta confesión voluntaria no llevaba aparejada ninguna pena ni castigo, pero los que acudian a ella quedaban como «reconciliados», de tal forma que

6 El sambenito era un capotillo o especie de escapulario que Hevaban en los autos de fe los penitentes condenados o reconciliados por la Inquisición.

Asimismo, se denominan de este modo los letreros que se ponían en las iglesias con el nombre y castigo de los penitenciados.

7 Esta relación se conserva en el Archivo Histórico Nacional (AHN), Sección de Inquisición, libro 789 , fols. $244 \vee-247 \vee$, y ha sido publicada en mi trabajo «nquisición de Logroño: Sambenitos del siglo xvl», en Berceo, n. 103 (1982), págs. 51-68.

8 Esta nómina se conserva en el Archivo Histórico Nacional, Sección de Inquisición, libro 790, fols. $90 \mathrm{r}-99 \mathrm{v}$. 
si incurrían nuevamente en los mismos errores serían procesados como «relapsos» (reincidentes tras la reconciliación) y condenados a relajación.

La larga lista de setenta y cuatro moriscos reconciliados que figuran en esta relación concluye indicando que

"todas las personas suso dichas fueron públicamente reconciliadas en un día de fiesta, en la iglesia del monasterio del señor San Agustín de Ágreda, a la misa mayor, en que hubo sermón. E allí abjuraron sus herrores y fueron absueltos y penitenciados, habiéndose leído una sentencia general contra todos, conforme al edicto de gracia, que se confesasen en el plazo de quince días, generalmente, de todos sus pecados con uno de los confesores del dicho monasterio y del señor San Julián de la dicha villa, y sacasen dello cédula y la entregasen al comisario de la Inquisición que allí reside, para que las remitiese a la Inquisición, y ayunasen los siete viernes de Entrepascua y Pascua, y en cada uno de ellos rezasen el Rosario de Nuestra Señora».

Esta relación es particularmente interesante porque nos informa de manera detallada acerca de la actividad profesional desarrollada por la mayor parte de los moriscos que figuran en la misma, así como sobre su edad y la de su conversión al islamismo, sus «maestros» en la religión musulmana, etc.

La fusión de ambas nóminas nos ofrece un cuadro bastante completo de la comunidad morisca de Ágreda en los últimos decenios del siglo XVI, a través de un total de ciento ocho de sus miembros que, sin duda, constituían una parte especialmente significativa de esta comunidad.

\section{PRECEDENTES DE LA COMUNIDAD MORISCA DE ÁGREDA: LA ALJAMA MUDÉJAR A FINES DEL SIGLOXV}

A lo largo de la Baja Edad Media, Ágreda conoció la presencia de una importante comunidad mudéjar, la más sobresaliente y numerosa de toda la comarca nororiental de Castilla y' una de las diez aljamas mudéjares más voluminosas de la Corona castellana ${ }^{9}$. Su especial desarrollo se encuentra, probablemente, en estrecha relación con el auge comercial y manufacturero que disfrutó esta población soriana a partir de los últimos decenios del siglo XV.

9 Algunas noticias sobre esta aljama pueden encontrarse en mi trabajo titulado "Las comunidades mudéjares de las diócesis de Osma y Sigüenza a fines de la Edad Media", en Espacio, Tiempo y Forma. Revista de la Facultad de Geografía e Historia de la UNED (Serie III. Historia Medieval), n. 4 (1989), págs. 137-173. 
La historia de Ágreda y de su tierra se define, ante todo, por su carácter fronterizo con el reino de Aragón, de forma que su auténtica razón de ser durante la Edad Media fue la de baluarte en el dispositivo fronterizo del reino de Castilla frente a Aragón. En este contexto, la presencia mudéjar constituye en toda la comarca nororiental de Castilla un fenómeno en cierto modo complementario del mudejarismo aragonés ${ }^{10}$.

La villa de Ágreda se encuentra muy próxima a las comarcas aragonesas de Borja y Tarazona y a la navarra de Tudela, todas ellas de fuerte presencia mudéjar desde los tiempos de su recoriquista. En la comarca de Tarazona — valle del río Queiles - había comunidades mudéjares en Tarazona, Santa Cruz del Moncayo, Torrellas, Grisel, Tórtoles, Vierlas, Cunchillas y Novallas; en la comarca de Borja — valle del río Huecha-, en Borja, Malejón, Albeta, Burela, Bisimbre, Agón y Fréscano; en la comarca de Tudela — valle del río Ebro_, en Tudela, Fontellas, Ribaforada, Cortes, Murchante, Urzarte, Pedriz, Ablitas, Barrillas, Monteagudo, Tulebras, Cascante, Fitero, Cintruénigo, Corella, Cadreita, Valtierra y Arguedas.

En definitiva, la ubicación geográfica de Ágreda y su proximidad a las antedichas comarcas aragonesas y navarra explican muchos de los rasgos propios de la comunidad mudéjar de esta población soriana y de sus condicionamientos históricos. En este sentido, y como tendremos más adelante ocasión de comprobar, las relaciones entre las comunidades mudéjares y moriscas castellanas y aragonesas fueron tradicionalmente muy intensas a lo largo de toda la Baja Edad Media y comienzos de la Edad Moderna ${ }^{11}$.

A fines del siglo XV la comunidad mudéjar de Ágreda llegó a estar integrada por unos 100 a 120 vecinos, lo que equivale a unos 600 individuos, aplicando un índice de base 5 , es decir calculando cinco personas por cada vecindad. Las distintas noticias de que se dispone parecen confirmar la hipótesis que señala que en el año 1502 la mayor parte de los miembros de esta comunidad se convirtió al cristianismo, tras la promulgación del edicto de expulsión de los mudéjares de Castilla. La conversión a la religión cristiana permitía a los mudéjares permanecer en sus lugares habituales de residencia y conservar la propiedad de todos sus bienes. A cambio, desde este momento quedaban sujetos a la estrecha vigilancia de la Inquisición.

\footnotetext{
10 Ladero Quesada, Miguel Angel, «Los mudéjares de Castilla en la Baja Edad Media», en Actas del / Simposio Internacional de Mudejarismo, Madrid - Teruel. CSIC, Instituto de Estudios Turolenses, 1981, págs. 349-390. (En concreto, vease pág. 356).

Garcia-ARENAL, Mercedes, Inquisición y moriscos. Los procesos del tribunal de Cuenca. Madrid, Siglo XXI, 1983 (2. edición), págs. 80-82.
} 
La señal que de forma más fehaciente confirma la hipótesis de la conversión masiva de mudéjares al cristianismo en el año 1502 es el elevado número de moriscos que figuran en la documentación inquisitorial a lo largo del siglo XVI, tanto en Ágreda como en otras poblaciones castellanas próximas a la frontera de Aragón —Deza, Arcos de Jalón, Molina de Aragón-que a fines de la Edad Media contaron con la presencia de aljamas mudéjares de cierta importancia.

Se trata de una población morisca de origen mayoritariamente antiguo, de forma que son escasos los moriscos que llegaron procedentes del reino de Granada después de su expulsión en 1570. En general, es una población bastante homogénea y descendiente directa de los mudéjares que residían en las mismas localidades antes de la promulgación del edicto de expulsión de 1502.

Como se ha señalado anteriormente, durante todo el siglo Xvı fueron constantes las relaciones, incluso de parentesco, entre familias moriscas que residían en núcleos de población situados a uno y otro lado de la línea que separaba los reinos de Castilla y Aragón, comarca ésta de fuerte presencia morisca.

Por último, en el año 1609 figuran 24 fuegos moriscos en Ágreda, en el censo realizado siguiendo instrucciones del Consejo de Estado ${ }^{12}$. Un año después, en la relación de moriscos que se registraron ante el conde de Salazar en la ciudad de Burgos, para salir a Francia, aparecen 19 "casas" de Ágreda, que hacían un total de 96 individuos ${ }^{13}$. Del mismo año 1610 se conserva también otra interesante relación elaborada por el conde de Salazar, en la que se recogen noticias sobre los moriscos que permanecieron en el reino de Castilla tras la expulsión de 1610; por lo que respecta a Ágreda se dice textualmente:

«En esta villa an quedado diez casas de moriscos pobres, y se a enbiado orden al corregidor las encamine a un lugar más allá de Burgos, donde se an de juntar con otros de aquel partidow ${ }^{14}$.

\section{LOS MORISCOS DE ÁGREDA A FINES DEL SIGLO XVI: ASPECTOS DEMOGRÁFICOS, ECONÓMICO-SOCIALES Y RELIGIOSOS}

Según se ha indicado en otro lugar, el análisis detallado de las nóminas que constituyen el objeto de este trabajo permiten trazar un cuadro bas-

\footnotetext{
12 Lapeyre, Henri, Géographie de l'Espagne morisque. París 1959. (Véanse págs. 164-165).

13 Ibidem, págs. 198 y 252.

14 lbidem, págs. 254-259.
} 
tante completo sobre la realidad del problema morisco en la villa de Ágreda en los últimos decenios del siglo xvI.

El número total de moriscos vecinos de Ágreda documentados a través de estas nóminas es de 108, de los que 54 son varones y los otros 54 mujeres. A juzgar por las cifras relativas a la expulsión de los moriscos en el año 1610, a las que se hace mención en el apartado anterior, es probable que los moriscos documentados a través de las nóminas de 1583 y 1588 constituyan cerca de las dos terceras partes del total de la comunidad.

De las 54 mujeres relacionadas, tan sólo figura una como soltera; las 53 restantes son casadas, si bien 22 de ellas se encontraban en estado de viudedad.

Por lo que respecta a los varones, los datos son más inciertos por cuanto, de forma contraria a lo que sucede con las mujeres, no se indica si estaban o no casados. La gran mayoría debían estar casados, pero lo cierto es que esta circunstancia sólo nos consta en 23 casos.

Asimismo, entre los moriscos documentados aparecen 23 matrimonios, es decir 46 individuos, lo que equivale a un $42,5 \%$ del total.

Como tendremos ocasión de ver con mayor detalle, se trata de gentes sencillas, con escasos conocimientos religiosos, y que nos ofrecen una buena imagen de lo que debía ser la vida cotidiana en una comunidad morisca castellana.

A través de estas nóminas conocemos la "estructura de edades» de la comunidad morisca de Ágreda a fines del siglo XVI, que se puede sintetizar en el siguiente gráfico:

\begin{tabular}{ccc}
\hline Edad & Varones & Mujeres \\
\hline Menores de 25 años & 2 & - \\
25 a 30 años & 1 & 16 \\
30 a 35 años & 8 & 9 \\
35 a 40 años & 7 & 4 \\
40 a 45 años & 6 & - \\
45 a 50 años & 3 & 4 \\
50 a 55 años & 4 & - \\
55 a 60 años & - & 3 \\
\hline
\end{tabular}

En general, es fácil apreciar que la edad media de las mujeres es algo inferior a la de los hombres, de forma que si el $64 \%$ de las mujeres se sitúa entre los 25 y los 35 años, el $61,7 \%$ de los hombres cuenta entre 30 y 45 años de edad. 
Teniendo en cuenta que un número importante de los moriscos documentados forman matrimonio, no llama excesivamente la atención la menor edad proporcional de las mujeres, habida cuenta que éstas accedían a una edad más temprana al matrimonio. En cualquier caso, la edad media de la población morisca de Ágreda documentada se sitúa en el arco de los 30 a los 40 años -es importante hacer notas que en estas nóminas no aparece, lógicamente, ningún niño-, lo que tampoco debe parecer extraño en una época en la que la esperanza de vida no era muy alta.

Por otra parte, las nóminas nos ofrecen también una completísima información sobre las "actividades socio-profesionales» desempeñadas por los moriscos vecinos de Ágreda. Así, de los 68 varones documentados -algunos ya fallecidos--, nos informan sobre la dedicación profesional de 61 de ellos, es decir el $89,7 \%$, que es un porcentaje ciertamente excepcional.

El análisis documental permite señalar un predominio absoluto de las actividades artesanales, sobresaliendo de forma muy particular los oficios relacionados con los sectores metalúrgico y del cuero.

En mi opinión, no parece de ningún modo exagerado hablar de un monopolio del trabajo del hierro en Ágreda por parte de los moriscos, pues en los años setenta y ochenta del siglo xvı figuran documentados un total de 27 herreros moriscos vecinos de esta población soriana. Asimismo, por las mismas fechas hay también noticias de un herrador, dos arcabuceros, un candilero y dos caldereros, oficios todos ellos en relación con el hierro.

El trabajo del cuero atraía también la atención de buen número de moriscos, de forma que la zapatería constituía, numéricamente, la segunda en importancia de las actividades profesionales ejercidas por los moriscos de Ágreda, con un total de 15 zapateros registrados. Del mismo modo, está también documentado un curtidor morisco.

Aunque en menor medida, hay también noticias sobre moriscos de Ágreda dedicados a otros diversos oficios artesanales, tanto del sector textil —un tejedor y un tejedor de lienzos-, como de la alfarería - tres olleros, propietarios de pequeños talleres o alfares de carácter familiar, donde se elaborarían distintos útiles imprescindibles para la vida doméstica-, de la carpintería - un fustero-, o de la platería - un platero-.

Teniendo en cuenta el carácter fronterizo de esta población, es muy probable que algunos moriscos se dedicaran también al oficio de la arriería y trajinería, dedicándose a un comercio de corto radio que les permitiría mantener unas intensas relaciones con las comunidades moriscas ara- 
gonesas próximas a la frontera. Sin embargo, y debido probablemente a que el ejercicio de la trajinería sería compatibilizado con otras actividades, tan sólo aparecen documentados un arriero y un trajinero.

Otros oficios tradicionalmente propios de los mudéjares y de los moriscos, como los relacionados con la construcción, están poco representados en Ágreda, y tan sólo figuran dos albañiles.

Por último, aparece también un confitero, dedicado a la elaboración y venta de dulces, lo que constituye también una tradición muy arraigada entre mudéjares y moriscos.

Como se ha señalado anteriormente, tan sólo en el caso de siete moriscos no se indica la actividad profesional ejercida. Es posible que estas siete personas se dedicaran al cultivo del campo, en especial de las huertas que rodeaban el recinto urbano, pero lo cierto es que nada seguro se sabe al respecto. Sin embargo, la falta de noticias acerca de moriscos ocupados en el trabajo de la tierra no debe llamar en exceso la atención, ya que la agricultura es una actividad que normalmente deja muy pocos vestigios documentales, por producirse en los niveles más humildes de la actividad humana. En este sentido, es muy probable que algunos moriscos compaginaran su prioritaria dedicación al ejercicio de un oficio artesanal con el cultivo de pequeñas parcelas y huertas próximas al recinto urbano.

La actividad profesional de los moriscos de Ágreda a fines del siglo XVI puede esquematizarse en el gráfico de la página siguiente.

Por último, las nóminas nos permiten también un acercamiento a la «vida religiosa» de los moriscos de Ágreda.

Las cifras relativas a moriscos de esta población penitenciados y/o reconciliados por la Inquisición son la señal más evidente de que continuaban fuertemente apegados a las costumbres y tradiciones islámicas, pese a que habían transcurrido ya varios decenios desde su conversión al cristianismo. En todo momento, los moriscos manifiestan una decidida voluntad de superviviencia como grupo propio y diferenciado, lo que se expresa en su firme decisión de perseverar en el cumplimiento de la religión musulmana, auténtico vínculo de unión entre ellos.

Pese a esto, en general eran ya muy escasos sus conocimientos del Islam, y los moriscos practicaban con frecuencia una religión ecléctica, con mezcla de elementos cristianos y musulmanes, pese a su decidida voluntad de cumplir fielmente con los preceptos islámicos. El ritual y el culto musulmanes se encontraban muy empobrecidos a fines del siglo XVI, de forma que en la documentación inquisitorial se repiten las mismas 
acusaciones, descritas del mismo modo, lo que hace pensar que se trata de un mero formulario que se aplica por igual a cualquier morisco acusado de apostasía ${ }^{15}$.

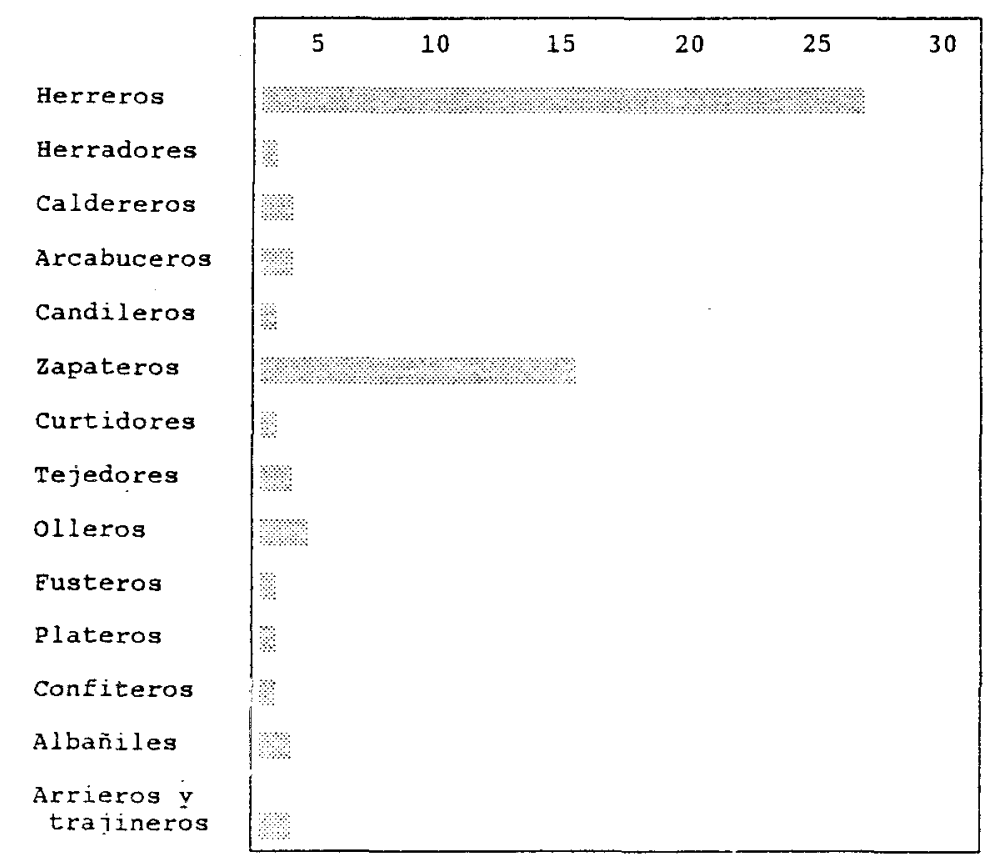

Aunque con ligeras variaciones, el texto de la acusación en la nómina de moriscos vecinos de Ágreda reconciliados en el año 1588 es muy similar en todos los casos, y sigue el siguiente esquema:

“... confesé haber sido moro de... años a esta parte, porque ciertas personas que declaró le hakían enseñado los ritos y ceremonias de la secta de moros: Cómo había de ayunar el ayuno del Ramadán y hacer el baño y çala, y rezar las oraciones y azoras del 'alhandu culuhuha' y 'Enatayneca y nanzaraneo y almuquilina', y declaró palabra por palabra las dichas azoras así como las sabía y se las habían enseñado. Y que aunque se había probado muchas veces, no había podido ayunar el dicho ayuno del Ramadán los treinta días enteros, ni sabía hacer el baño ni la çala, aunque en su corazón siempre las hacía. Y que había rezado todas

15 García-Arenal, Mercedes, Op. cit., pág. 46. 
las veces que había podido durante el tiempo de los... años que había sido moro" $" 16$.

No cabe la menor duda de que las prácticas religiosas islámicas más frecuentes entre los moriscos eran el ayuno del Ramadán, la oración y las abluciones. Entre ellas, el ayuno del Ramadán es el último rito musulmán en perderse, manteniéndose a veces en algunas personas que, por lo demás, parecen plenamente integradas en el cristianismo. Esto obedece a que, más allá de una simple práctica re!igiosa, el Ramadán es un signo de diferenciación cultural.

No obstante, en el siglo xvı no es ya frecuente que los moriscos guarden el ayuno en su integridad, y muchos se contentan con cumplirlo tan sólo unos días del mes. Algunos moriscos, incluso, señalan que habían intentado guardar el ayuno íntegramente, pero que no habían podido cumplirlo más allá del primer mediodía. Aunque en algunos casos las testificaciones de los moriscos ante el tribunal de la Inquisición estén deliberadamente exageradas, con el fin de recibir una pena más leve, no cabe duda de que a fines del siglo Xvı los moriscos ya no sentían la obligación de respetar estrictamente el ayuno; es posible también que su cumplimiento parcial obedezca al intento de evitar sospechas por parte de los convecinos cristianos.

El empobrecimiento de la cultura religiosa de los moriscos se manifiesta también en la práctica de la oración, que constituye otro de los cinco postulados básicos del Islam. Así, pese a que con frecuencia se indica en las nóminas que los moriscos de Ágreda repetían textualmente ante el tribunal de la Inquisición diversas azoras del Corán, todo hace pensar que con frecuencia desconocían su auténtico significado lo que, fundamentalmente, obedece a que a fines del siglo XVI eran muy pocos los moriscos que conocían, siquiera de forma mínima, la lengua árabe. Cuando disponian de algún libro religioso o de un oracional en árabe, debían acudir a algún morisco de Aragón para que se lo leyera.

Asimismo, hay también moriscos que afirman desconocer cómo se hace la «çala», es decir el baño ritual que todo musulmán debe hacer antes de la primera oración del día, así como los viernes y otras diversas festividades del calendario litúrgico islámico. Pese a todo, ésta es una práctica habitual entre los moriscos de Ágreda, cuyo cumplimiento parece que respetan de forma más estricta las mujeres que los hombres.

16 AHN, inquisición, libro 790, fols. $90 \mathrm{r}-99 \mathrm{v}$. 
Sin embargo, en las nóminas que constituyen el objeto de este trabajo no aparecen referencias a otras ceremonias y ritos de la religión islámica, como las «hadas" o ceremonias de imposición del nombre a los niños recién nacidos, o las bodas y enterramientos con arreglo al ritual musulmán. Tampoco hay alusiones a las prácticas y costumbres alimenticias de los moriscos, aunque no cabe la menor duda de que en este aspecto concreto se mantendrían estrechamente ligados a las costumbres y tradiciones musulmanas - rechazo absoluto al consumo de carne de cerdo, así como a cocinar con grasa animal- pues al mandato religioso se unía la práctica de una cocina propiamente mediterránea, basada en el uso del aceite vegetal.

En definitiva, a fines del siglo Xvı la religión musulmana está ya muy empobrecida entre las comunidades moriscas castellanas, lo que es el resultado de los largos años de convivencia con los cristianos, así como de la dispersión de la población morisca y de sus mínimas posibilidades de mantener una vida comunitaria por la estrecha vigilancia a que eran sometidos por la Inquisición. Por este motivo, los moriscos de Ágreda se esforzaban por mantener frecuentes contactos con moriscos de poblaciones aragonesas próximas, mucho más instruidos desde el punto de vista religioso, y quienes en numerosas ocasiones actuaban como sus maestros en materia de religión.

El reino de Aragón jugaba también muchas veces el papel de refugio para los moriscos de Ágreda y de otras poblaciones castellanas próximas a la frontera, especialmente en los momentos en que se activaba la actuación inquisitorial. En el caso concreto de Ágreda, las nóminas nos informan que 27 moriscos de esta población permanecieron durante algún tiempo en el reino de Aragón, por temor a la Inquisición. Se trata de dieciséis varones y de once mujeres, y pese a que en ningún caso se indica en qué poblaciones se establecieron, sin duda fue en alguna población fronteriza donde residían familias moriscas con las que mantenían estrechas relaciones.

El temor a la Inquisición obligaba a los moriscos criptomusulmanes a conservar las estructuras de la vida religiosa en la intimidad de los hogares. El estudio de la documentación inquisitorial permite observar cómo las familias criptomusulmanas más firmes en sus creencias dieron lugar a auténticas dinastías de penitenciados por la Inquisición. Como ha señalado Mercedes García-Arenal para los moriscos del tribunal de la Inquisición de Cuenca, estas familias emparentaban frecuentemente entre sí, lo que contribuía decisivamente a la impermeabilidad del grupo ${ }^{17}$.

7 Garcia-Arenal, Mercedes, Op. cit., pág. 29. 
En el caso concreto de Ágreda destacan en este sentido la familia Platero, con trece de sus miembros en las nóminas inquisitoriales de 1583 y 1588; la familia Ballestero, con once; y la familia Lanzero, con ocho.

Entre los moriscos, al igual que sucede con los judeoconversos, la mujer tuvo un papel de primera importancia en el mantenimiento de las tradiciones, costumbres y ritos propios de la religión musulmana, así como en su transmisión a los niños y jóvenes de la familia.

Numerosos testimonios dan fe del mayor conservadurismo de las mujeres en materia religiosa. En el «nforme acerca de la instrucción de los moriscos" de Valencia se hace hincapié en que se procure que todos asistan a las clases en que se instruía sobre la doctrina cristiana, "y en special las mugeres, que stán más obstinadas» ${ }^{18}$. Según Mercedes García-Arenal, la firmeza del islamismo en una determinada población o comarca se encuentra en relación directamente proporcional al número de mujeres procesadas. Para la misma autora, las poblaciones en las que, a pesar de que la población morisca es numerosa, escasean los procesos inquisitoriales contra mujeres se encuentran en una fase más avanzada en el proceso de asimilación a la sociedad castellana ${ }^{19}$.

Por lo que se refiere a la distribución de los penitenciados por la Inquisición entre los dos sexos, lo más frecuente es que exista una gran homogeneidad. Así, de los 95 moriscos vecinos de Arcos de Jalón que fueron procesados a lo largo del siglo XVI por el tribunal de Cuenca, 40 eran mujeres; y en el caso de la también población soriana de Deza, de un total de 93 procesados, 53 eran mujeres. Lo mismo ha corroborado Ricardo García Cárcel para el tribunal de Valencia ${ }^{20}$.

En el caso concreto de Ágreda, y según ha sido señalado con anterioridad, de los 108 moriscos penitenciados o reconciliados por la inquisición de los que tenemos noticia, la mitad exactamente - es decir 54eran mujeres.

Otro dato que abona la tesis del importantísimo papel jugado por la mujer en la conservación de la religión y de las costumbres musulmanas en el seno de las familias conversas, es el elevado número de mujeres que son señaladas por los penitenciados como sus «maestras» en la fe islámica.

\footnotetext{
18 Boronat y Barrachina, Pascual, Los moriscos españoles y su expuisión. Estudio histórico crítico. Valencia 1901

19 Garcia-Arenal, Mercedes, Op. cit., pág. 27.

20 García CÁrcel, Ricardo, Orígenes de la Inquisición española. El tribunal de Valencia, 1478-1530. Barcelona 1976. (Véase pág. 167).
} 
Los ochenta vecinos de Ágreda que fueron reconciliados en el año 1588 por el tribunal de la Inquisición nos informan, a través de su declaración, de las personas que actuaron como sus inductores en la religión musulmana, lo que constituye una información de gran interés. En 29 casos se indica que fueron instruidos en el Islam por "cierta persona", sin duda con el ánimo de no delatar a familiares, vecinos o amigos. Pero en los 41 casos restantes se señalan con detalle las personas que actuaron como «maestros» y transmisores de la religión musulmana. Son los siguientes, indicándose el número de veces que figuran como tales:

\begin{tabular}{lrll}
\hline Madres: & 13 & Padres: & 6 \\
Padre y madre: & 1 & Abuelas: & 4 \\
Tías: & 4 & Tíos: & 4 \\
Maridos: & 6 & Amos y patrones: & 3 \\
\hline
\end{tabular}

Como es fácilmente apreciable, madres, abuelas y tías constituyen, en conjunto, un porcentaje significativo entre los miembros de la familia encargados de adoctrinar en el Islam a los niños y jóvenes del núcleo familiar. Asimismo, llama también la atención el elevado número de mujeres que fueron instruidas en el Islam por sus maridos; en todos estos casos se trata de mujeres muy jóvenes, siempre menores de veinte años. Por el contrario, no está documentado ningún caso en que un hombre fuera adoctrinado por su mujer, lo que es una señal inequívoca del papel dominante ejercido por el hombre en el seno de la familia.

También son de destacar los tres casos en los que jóvenes moriscos son adoctrinados en la fe islámica por sus amos o patrones, así mismo moriscos. En los tres casos son jóvenes de corta edad en el momento en que abrazan el islamismo lo que, unido a su condición de criados o de aprendices en la casa o taller de aquéllos, explica claramente la influencia que sobre ellos ejercían o podían ejercer.

Por último, con el fin de evitar indiscreciones que pudieran delatarles ante sus vecinos, las familias moriscas - del mismo modo que hacían las familias judeoconversas- mantenían a los niños totalmente ajenos a la religión musulmana hasta que alcanzaban una edad que garantizaba la discreción. En este momento, la instrucción en la fe islámica corría a cargo generalmente de un miembro de la familia, según acabamos de señalar.

Por lo que respecta en concreto a la comunidad morisca de Ágreda, los datos que poseemos relativos a la edad de conversión al islamismo 
de 72 de sus miembros confirman plenamente la anterior afirmación. Estos datos son los siguientes:

\begin{tabular}{cr}
\hline Edad de conversión al islam \\
\hline Menores de 10 años: & 1 \\
De 10 a 14 años: & 27 \\
De 15 a 19 años: & 30 \\
De 20 a 24 años: & 9 \\
De 25 a 29 años: & 3 \\
De 30 a 40 años: & 2 \\
TOTAL: & 72 \\
\hline
\end{tabular}

En definitiva, el $79 \%$ de las conversiones se producen cuando el niño - joven cuenta entre 10 y 19 años, concentrándose fundamentalmente entre los 12 y los 17 años; era ésta una edad apropiada para el adoctrinamiento, ya que si por una parte la escasa edad hacía todavía al niño muy receptivo a las enseñanzas, por otra parte ya era una edad que garantizaba la discreción.

Para concluir este trabajo, seguidamente se relacionan todos los moriscos vecinos de Ágreda que figuran en las nóminas inquitoriales de 1583 y 1588, indicándose en cada caso los aspectos más relevantes que conocemos sobre cada uno de ellos.

a. Relación de sambenitos correspondientes a moriscos conversos vecinos de Ágreda que en el año 1583 se encontraban expuestos en la Iglesia Colegial de Logroño.

1. AQUEN, María.

Vecina de Agreda. Viuda de Miguel Platero, herrero.

De generación de conversos moros.

Reconciliada por hereje apóstata mora en 1578.

2. AQUENA, Francisca, alias de la Huerta.

Vecina de Ágreda. Mujer de Leonís de la Huerta, herrador.

De generación de conversos moros.

Reconciliada por hereje apóstata mora en 1580.

3. AQUENA, Leonor la.

Vecina de Ágreda. Mujer de Hernando Atorro, curtidor. 
De generación de conversos de moros.

Ausente, relajada en estatua por hereje apóstata en 1580.

4. ATORRO, García.

Vecino de Ágreda. Hijo de Hernando Atorro.

De generación de conversos de moros.

Reconciliado por hereje apóstata en 1578.

5. ATORRO, Hernando.

Vecino de Ágreda. Curtidor, Casado con Leonor la Aquena, y padre de García Atorro.

De generación de conversos de moros.

Reconciliado por hereje apóstata en 1578.

6. BALLESTERA, María.

Vecina de Ágreda. Viuda de Juan Lanzero, ollero.

De generación de moros.

Relajada en estatua y condenada su fama y su memoria por hereje apóstata mora en 1583.

7. BALLESTERO, Francisco.

Vecino de Ágreda. Arcabucero.

De generación de conversos de moros.

Reconciliado por hereje apóstata en 1577.

8. BALLESTERO, Francisco.

Vecino de Ágreda. Herrero.

Hijo de Francisco Vallestero. De generación de nuevos convertioios de moros.

Ausente, relajado en estatua por hereje apóstata en 1580.

9. BALLESTERO, Gabriel.

Vecino de Ágreda.

Cristiano nuevo de moro.

Reconciliado por hereje apóstata en 1529.

10. BALLESTERO, Gracia.

Vecina de Ágreda. Mujer de Gabriel Cardero, herrero.

De generación de moros.

Relajada en estatua por hereje mora, en 1583.

Ausente contumaz.

11. BALLESTERO, Leonor.

Vecina de Ágreda. Viuda de Gabriel Lanzero.

De generación de moros.

Relajada en estatua y condenada su memoria y fama por hereje apóstata mora en 1583. 
12. BALLESTERO, María.

Vecina de Ágreda. Mujer de Francisco Corazón.

De generación de conversos de moros.

Ausente, relajada en estatua por hereje apóstata en 1580.

13. BARRIONUEVO, Hernando de.

Vecino de Ágreda. Zapatero.

Reconciliado.

14. BARRIONUEVO, Pedro de.

Vecino de Ágreda. Zapatero.

De generación de conversos de moros.

Ausente relajado en estatua por hereje apóstata en 1580.

15. CALLE, Juan de la.

Vecino de Ágreda. Herrero.

De generación de moros.

Reconciliado por hereje apóstata moro en 1578.

16. CARDERO, Gabriel.

Vecino de Ágreda. Herrero. Casado con Gracia Ballestero.

De generación de conversos de moros.

Reconciliado por hereje apóstata moro en 1577.

17. CARRASCÓN, «el mayor», García.

Vecino de Ágreda. Zapatero. Padre de García Carrascón «el mozo» y de Lope Carrascón.

De goneración de moros.

Relajado en estatua por hereje apóstata moro, en 1583.

Ausente contumaz.

18. CARRASCÓN, «el mozo», García.

Vecino de Ágreda. Hijo de García Carrascón «el mayor».

De generación de nuevos convertidos de moros.

Ausente, relajado en estatua por hereje apóstata en 1580.

19. CARRASCÓN, Lope.

Vecino de Ágreda. Zapatero.

Hijo de García Carrascón «el mayor».

De generación de conversos de moros.

Reconciliado por hereje apóstata moro en 1578.

20. CASTEJÓN, Martín de.

Vecino de Ágreda. Tejedor.

Cristiano nuevo de moro.

Reconciliado por hereje apóstata en 1529.

21. CORAZÓN, Lope. 
Vecino de Ágreda.

Reconciliado y condenado a cárcel perpetua.

22. ESGUEVA, María de.

Vecina de Ágreda. Mujer de Diego Ruiz de Esgueva.

Cristiana nueva de moros.

Reconciliada por hereje apóstata en 1529.

23. HATI, Juan de.

Vecino de Ágreda.

De generación de conversos de moros.

Ausente, relajado en estatua por hereje apóstata en 1580 .

24. IZQUIERDA, Leonor la.

Vecina de Ágreda. Viuda de Juan Ruiz, platero.

De generación de conversos de moros.

Reconciliada por hereje apóstata en 1577.

25. IZQUIERDO, Hernando (?).

Vecino de Ágreda. Herrero.

De generación de nuevos convertidos de moros.

Ausente, relajado en estatua por hereje apóstata en 1580.

26. IZQUIERDO, Lope.

Vecino de Ágreda. Hijo de Miguel Izquierdo.

De generación de conversos de moros.

Ausente, relajado en estatua por hereje apóstata en 1580.

27. JORDÁN, Juan.

Vecino de Ágreda. Zapatero. Casado con María de Peñafiel.

De generación de conversos moros.

Ausente, relajado en estatua por hereje apóstata en 1580.

28. LAGARZESA, María.

Vecina de Ágreda. Mujer de Tristán de Esgueva.

Cristiana nueva, de generación de moros.

Reconciliada por hereje apóstata er 1529.

29. LANZERA, Leonor.

Vecina de Ágreda. Viuda de Diego de Marzo, trajinero, y después de Diego de Peñafiel, fustero.

De generación de conversos de moros.

Reconciliada por hereje apóstata en 1580.

30. LANZERO, Miguel.

Vecino de Ágreda. Herrero.

Hijo de Gabriel Lanzero.

De generación de conversos de moros. 
Reconciliado por hereje apóstata moro en 1578.

31. MEDINA, María de.

Vecina de Ágreda. Mujer de Francisco Atorro.

De generación de conversos de moros.

Reconciliada por hereje apóstata mora en 1578.

32. MEDINA, Miguel de.

Vecino de Ágreda. Calderero. Casado con Ana Platera. Hijo de Pedro de Medina y de Esgueva su mujer.

De generación de moros.

Relajado en estatua y condenada su memoria y fama por hereje apóstata moro en 1583

33. PARIENTE, Ana.

Vecina de Ágreda. Mujer de Gabriel Ballestero.

De generación de conversos de moros.

Reconciliada por hereje apóstata en 1577.

34. PARRA, Águeda de.

Mujer de Juan de Valdeguía. Vecina de Ágreda.

De generación de conversos de moros.

Reconciliada por hereje apóstata en 1578.

35. PEÑAFIEL, María de.

Vecina de Ágreda. Mujer de Juan Jordán, zapatero.

De generación de conversos de moros.

Ausente, relajada en estatua por hereje apóstata en 1580 .

36. PLATERA, Ana.

Vecina de Ágreda. Mujer de Miguel de Medina, calderero.

De generación de conversos de moros.

Reconciliada por hereje apóstata mora en 1578.

37. PLATERO, Gabriel.

Vecino de Ágreda.

De generación de moros.

Ausente, relajado en estatua por hereje apóstata, en 1580.

38. PLATERO, Juan.

Vecino de Ágreda. Herrero.

Hijo de Hernando Platero.

De generación de conversos de moros.

Reconciliado por hereje apóstata moro en 1578.

39. SASTRE, Francisco el.

Vecino de Ágreda. Herrero.

De generación de conversos de moros. 
Relajado en estatua y condenada su memoria y fama por hereje apóstata moro en 1583.

40. SEGOVIA, María de.

Vecina de Ágreda. Mujer de Hernando Toledano.

De generación de moros.

Reconciliada por hereje apóstata mora en 1578.

41. SERRANO, Miguel.

Vecino de Ágreda. Calderero.

De generación de conversos de moros.

Reconciliado por hereje apóstata moro en 1578.

42. TURIENZO, Isabel de.

Vecina de Ágreda. Mujer de Alonso de Villanueva, alias «Castellanos».

De generación de conversos moros.

Reconciliada por hereje apóstata mora en 1578.

43. YANGUAS, Alonso de.

Cristiano nuevo de moro. Zapatero.

Vecino de Ágreda.

Reconciliado por hereje apóstata en 1536.

b. Relación de moriscos vecinos de Ágreda reconciliados en el edicto de gracia dado en 1588.

1. ADEMEL, (nombre ilegible).

Vecino de Ágreda. Herrero.

De 50 años de edad.

Confesó ser moro hacía veintiocho años, enseñado por su madre cuando tenía 20 ó 22 años de edad.

Declaró los nombres de algunas personas con las que había realizado los ritos y ceremonias del Islam.

2. AQUEN, Lope.

Vecino de Ágreda. Herrero. Casado con María del Redal.

De 42 años de edad.

Confesó haber sido moro durante veinte años, porque le había enseñado cierta persona, hacía 20 ó 22 años.

Declaró los nombres de algunas personas con las que había realizado los ritos y ceremonias del Islam.

3. ARÉVALO, Francisco de.

Vecino de Ágreda. Zapatero. Casado con Gracia la Ballestera.

De 35 años de edad. 
Confesó ser moro desde hacía veinte años, porque le había enseñado esta religión su madre.

Declaró que también su mujer había cumplido algún rito islámico.

4. ARNEDO, Lope de.

Vecino de Ágreda. Zapatero.

De 60 años de edad.

Confesó ser moro desde hacía más de cuarenta años, enseñado por un amo suyo con quien estaba de aprendiz.

Declaró los nombres de algunas personas con las que había realizado los ritos y ceremonias del Islam.

5. BALLESTERA, Gracia la.

Vecina de Ágreda. Mujer de Francisco de Arévalo, zapatero.

De 32 años de edad.

Confesó ser mora desde hacía dieciocho años, porque le enseñó esta religión una persona que nombró.

6. BALLESTERO, Alexandre.

Vecino de Ágreda. Herrero. Casado con María de la Huerta.

De 36 ó 37 años de edad.

Confesó ser moro desde hacía dieciocho años, porque le enseñó esta religión cierta persona.

Por miedo al Santo Oficio había pasado al reino de Aragón, donde había estado durante algún tiempo.

7. BALLESTERO, Gabriel.

Vecino de Ágreda. Herrero.

De 50 años de edad.

Confesó ser moro desde hacía veintidós años, enseñado por su madre.

Declaró como cómplice a una hermana suya.

Por temor a la Inquisición, se ausentó de Ágreda durante un tiempo.

8. BALLESTERO, Lope.

Vecino de Ágreda. Herrero. Casado con Leonor la Platera.

De 40 años de edad.

Confesó ser moro desde hacía dieciséis años, enseñado por tres personas que nombró.

Declaró que había tratado sobre la religión islámica con sus «maestros» y con su mujer.

9. BARRIONUEVO, Francisco de.

Vecino de Ágreda. Herrero. Casado con Leonor la Castellana.

De 40 años de edad.

Confesó ser moro desde hacía veinte años, porque le enseñó esta religión una tía suya. 
10. CAMARGO, Isabel de.

Vecina de Ágreda. Mujer de Miguel Salazar, zapatero.

De 28 años de edad.

Confesó ser mora desde hacía quince años, enseñada por dos personas que nombró.

Declaró los nombres de algunas personas que cumplían los ritos musulmanes, entre ellas su marido.

Por miedo a la Inquisición, estuvo algún tiempo en el reino de Aragón.

11. CAMARGO, Leonor de.

Vecina de Ágreda. Mujer de Alexandre Platero, herrero.

De 28 años de edad.

Confesó ser mora desde hacía trece años, enseñada por su marido al contraer matrimonio.

12. CAMARGO, María de.

Vecina de Ágreda. Viuda de Miguel de Arévalo.

De 26 años de edad.

Confesó ser mora desde hacía diez años, enseñada por su madre.

Por temor a la Inquisición, se ausentó durante un tiempo en el reino de Aragón.

13. CARLOS, Francisco de.

Vecino de Ágreda. Zapatero.

De 22 años de edad.

Confesó ser moro durante cuatro años, porque cierta persona le enseñó esta religión.

14. CARRASCONA, María la.

Vecina de Ágreda. Mujer de Juan de Mendoza.

De 50 años de edad.

Confesó ser mora desde hacía cuarenta años, enseñada por su padre cuando tenía 10 u 11 años.

Por temor a la Inquisición se ausentó por un tiempo en el reino de Aragón. Declaró los nombres de algunas personas con las que trató sobre la religión islámica, y entre ellas su marido.

15. CASTELLANA, Isabel la.

Vecina de Ágreda. Mujer de Francisco de Soria, zapatero.

De 26 años de edad.

Confesó que, siendo muy pequeña, una abuela suya le había enseñado la religión islámica.

Señala por cómplices a su madre y hermana, y por maestra a su abuela.

16. CASTELLANA, Isabel la.

Vecina de Ágreda. Mujer de Francisco de Barrionuevo, herrero. 
De 32 años de edad.

Confesó ser mora desde hacía quince años, porque le había enseñado esta religión su abuela.

17. CASTELLANA, María la.

Vecina de Ágreda. Mujer de Lope la Muela, tejedor de lienzos.

De 34 años de edad.

Confesó ser mora desde hacía veinte años, porque cierta persona le había enseñado esta religión.

18. DOLAÇIZ, Miguel.

Vecino de Ágreda. Candilero herrero. Casado con María Lanzera, alias «eonor Lanzera».

De 52 años de edad.

Confesó ser moro desde hacía treinta y cuatro años, enseñado por una persona que nombró.

Por temor a la Inquisición, se ausentó en el reino de Aragón durante una temporada.

19. EZQUENA, Isabel.

Vecina de Ágreda. Viuda de Gabriel Falcón.

De 28 años de edad.

Confesó ser mora desde hacía quince años, enseñada por dos mujeres que nombró.

Por temor a la Inquisición, estuvo en el reino de Aragón durante un tiempo.

20. EZQUENA, María.

Vecina de Ágreda. Viuda de Diego Falcón.

De 35 ó 36 años de edad.

Confesó ser mora desde hacía dieciocho años, enseñada por una tía suya y por otra persona que citó.

21. GARCÉS, Isabel.

Vecina de Ágreda. Mujer de Martín de la Huerta, confitero.

De 38 ó 40 años de eclad.

Confesó ser mora desde hacía veinticinco años, enseñada por ciertas personas que nombró.

22. GARCÍA, Ana.

Vecina de Ágreda. Viuda de Blasco de Camargo.

De 40 años de edad.

Confesó ser mora desde hacía veintidós años, enseñada por cierta persona que nombró.

Declaró los nombres de algunas personas con las que había cumplido los ritos y ceremonias de la religión islámica. 
Por temor a la Inquisición, se ausentó en el reino de Aragón durante algún tiempo.

23. GENTO, Juan.

Vecino de Ágreda. Herrero.

De 42 años de edad.

Confesó ser moro durante trece años, desde que contaba con 17 años, enseñado por cierta persona que nombró.

Desde hacía doce años se había apartado del Islam, cuando prendieron a ciertas personas que nombró.

Declaró los nombres de ciertas personas con las que había realizado las ceremonias de la religión islámica.

Por temor a la Inquisición se ausentó de Ágreda.

24. HUERTA, Gabriel de la.

Vecino de Ágreda. Zapatero. Casado con María de Mendoza.

De 34 años de edad.

Confesó ser moro desde hacía veintidós años, enseñado por su madre.

Por temor a la Inquisición estuvo durante un tiempo en Aragón.

25. HUERTA, María de la.

Vecina de Ágreda. Mujer de Alexandre Ballestero, herrero.

De 28 años de edad.

Confesó ser mora desde hacía catorce años, porque al casarse, con 14 años, su marido le enseñó algunas cosas de esta religión.

Durante algún tiempo había estado con su marido en el reino de Aragón, por miedo al Santo Oficio.

26. HUERTA, Marín de la.

Vecino de Ágreda. Albañil.

De 22 años de edad.

Confesó ser moro desde hacía ocho años, porque estando en el reino de Aragón aprendiendo el oficio de tejedor, su amo le enseñó la religión musulmana.

Permaneció dos años en Aragón y prosteriormente regresó a Castilla; pese a que en su fuero interno era moro, no cumplía con los ritos ni con las ceremonias de la religión islámica por temor, por el gran número de los que prendía la Inquisición.

Poseía unos papeles escritos en «moriego", que había encontrado en casa de un converso del barrio, que había sido reconciliado, y que ya era difunto.

27. IZQUIERDO, Miguel.

Vecino de Ágreda. Zapatero.

De 38 años de edad. 
Confesó ser moro desde hacía veintidós años.

28. LANZERA, Ana.

Vecina de Ágreda. Mujer de Gabriel Lanzero, ollero.

De más de 25 años de edad.

Confesó ser mora desde hacía seis años, porque cuando se casó, con más de 18 años, le había enseñado esta religión cierta persona. Hasta entonces habia vivido como buena cristiana.

Señala que sólo había rezado las azoras que sabía, y que no había cumplido otros ritos islámicos porque no los conocía.

29. LANZERA, María, alias "Leonor Lanzera".

Vecina de Ágreda. Mujer de Miguel Dolaçiz, herrero candilero.

De 40 años de edad.

Confesó ser mora desde hacía veinticuatro años, enseñada por su madre. Declaró los nombres de algunas personas con quienes había tratado acerca de la religión islámica, entre ellas su marido.

30. LANZERA, María.

Vecina de Ágreda. Viuda de Guillermo de la Huerta.

De 37 ó 38 años de edad.

Confesó ser mora desde hacía dieciséis años, enseñada por cierta persona que nombró.

Declaró los nombres de algunas personas con las que había realizado los ritos y ceremonias del Islam.

31. LANZERO, Gabriel.

Vecino de Ágreda. Ollero. Casado con Ana Lanzera.

De más de 30 años de edad.

Confesó ser moro desde hacía dieciséis años, porque le enseñó cierta persona que nombró.

Declaró los nombres de algunas personas con las que había realizado los ritos y ceremonias del Islam.

32. LANZERO, Juan.

Vecino de Ágreda. Ollero.

De 45 años de edad.

Confesó ser moro por espacio de ocho años, enseñado por dos tíos suyos, con los que estuvo aprendiendo el oficio de ollero. Cuando se apartó del influjo de sus tíos se apartó del Islam.

33. LANZERO, Juan.

Vecino de Ágreda. Herrero.

De 30 años de edad.

Confesó ser moro desde hacía dieciséis años, enseñado por su madre. 
Declaró los nombres de algunas personas con las que había practicado la religión islámica.

34. LANZERO, Miguel (?).

Vecino de Ágreda. Tratante; oficial herrero.

De 46 años de edad.

Confesó ser moro desde hacía treinta años, enseñado por ciertas personas que nombró, primero, y después por su madre.

Declaró los nombres de algunas personas con las que había practicado la religión islámica.

35. MEDINA, Isabel de.

Vecina de Ágreda. Viuda de Alexandre Salazar.

De 28 años de edad.

Confesó ser mora desde hacía dieciséis años, porque le enseñó esta religión cierta persona.

36. MEDINA, Leonor de.

Vecina de Ágreda. Viuda de Juan Platero.

De 50 años de edad.

Confesó ser mora desde hacía treinta años, enseñada por ciertas personas que nombró.

37. MENDOZA, Juan de.

Vecino de Ágreda. Ollero. Casado con María la Carrascona.

De 60 años de edad.

Confesó ser moro desde hacía cuarenta y seis años, enseñado por un tío suyo.

Declaró los nombres de algunas personas con las que había practicado la religión islámica.

Por temor a la Inquisición, se ausentó en el reino de Aragón.

38. MENDOZA, María de.

Vecina de Ágreda. Mujer de Gabriel de la Huerta, zapatero.

De 30 años de edad.

Confesó ser mora desde hacía doce años, enseñada por cierta mujer que nombró.

39. MUELA, Lope la.

Vecino de Ágreda. Tejedor de lienzos. Casado con María la Castellana.

De 50 años de edad.

Confesó haber sido moro durante seis meses, cuando vivía con su amo en el reino de Aragón, hacía 30 años, porque su amo le había enseñado esta religión.

Cuando regresó a Castilla se apartó de los ritos del Islam.

40. MUELA, María de la. 
Vecina de Ágreda. Viuda de Francisco Castellano.

De 50 años de edad.

Confesó ser mora desde hacía treinta y cuatro años, enseñada por ciertas personas que nombró.

Declaró los nombres de algunas personas con las que había practicado la religión islámica.

41. NAVARRA, Leonor la.

Vecina de Ágreda. Viuda de Pedro de Medina.

De 60 años de edad.

Confesó ser mora desde hacía veintisiete años porque, estando viuda, dos personas le enseñaron la religión islámica.

Por miedo a la Inquisición, se ausentó una temporada en el reino de Aragón.

42. OZÉN, Alexandre.

Vecino de Ágreda. Herrero y arriero. Casado con Damiana Ruiz.

De 30 años de edad.

Confesó ser moro desde hacía veinte años.

43. OZÉN, Miguel.

Vecino de Ágreda. Herrero.

De 34 años de edad.

Confesó haber sido moro durante dos años, porque le enseñaron esta religión ciertas personas.

44. PALAÇIANA, Leonor la.

Vecina de Ágreda. Viuda de Lope Lanzero.

De 66 años de edad.

Confesó ser mora desde hacía veintisiete años. Al quedar viuda hacía 28 años, se recogió con su madre por haber quedado cargada de hijos y pobre, y ésta le enseñó la religión islámica.

Declaró los nombres de las personas a quienes había enseñado las oraciones y azoras, que eran sus hijos.

Por temor a la Inquisición, se trasladó al reino de Aragón con un hijo suyo.

45. PEÑAFIEL, Gabriel de.

Vecino de Ágreda. Oficial albañil.

De 48 años de edad.

Confesó ser moro durante dieciocho años, porque cuando tenía unos 18 años le había enseñado la religión islámica cierta persona que nombró.

Declaró por cómplice a su mujer.

Por temor a la Inquisición, se ausentó de Ágreda por un tiempo.

46. PLATERA, Francisca la. 
Vecina de Ágreda. Mujer de Diego Carlos, zapatero.

De 27 años de edad.

Confesó ser mora desde hacía quince años, porque teniendo 11 ó 12 años le había enseñado esta religión su madre.

47. PLATERA, Gracia la.

Vecina de Ágreda. Viuda de Juan del Redal.

De más de 25 años de edad.

Confesó vivir como mora desde hacía once años, porque le enseñó esta religión su madre.

48. PLATERA, Gracia la.

Vecina de Ágreda. Mujer de Miguel Serrano.

De 30 años de edad.

Confesó ser mora desde hacía diecisiete años.

49. PLATERA, Isabel la.

Vecina de Ágreda. Viuda de Juan Tristán.

De 30 años de edad.

Confesó ser mora desde hacía dieciséis años, porque cierta persona le había enseñado esta religión.

50. PLATERA, Leonor la.

Vecina de Ágreda. Mujer de Lope Ballestero, herrero.

De 30 años de edad.

Confesó ser mora desde hacía quince años, enseñada por cierta persona que nombró y por su marido.

Declaró los nombres de algunas personas con las que practicaba la religión islámica.

51. PLATERO, Alexandre.

Vecino de Ágreda. Herrero. Casado con Leonor de Camargo.

De 38 años de edad.

Confesó ser moro desde hacía veinticinco años, enseñado por un tío suyo.

Declaró como cómplice a su mujer.

52. PLATERO, Diego.

Vecino de Ágreda. Herrero.

De 30 años de edad.

Confesó ser moro desde hacía doce años, enseñado por cierta persona que nombró.

Declaró los nombres de algunas personas con las que practicaba la religión islámica.

53. PLATERO, Floristán.

Vecino de Ágreda. Herrero. 
De 36 años de edad.

Confesó ser moro desde hacía quince años, enseñado por un tío suyo.

Declaró los nombres de las personas con las que había practicado la religión islámica, entre ellas su mujer.

54. PLATERO, Leonís.

Vecino de Ágreda. Herrero. Casado con Gracia de Salazar.

De 36 ó 37 años de edad.

Confesó haber sido moro hacía diecisiete años, porque un tío suyo le enseñó la religión islámica.

55. PLATERO, Miguel.

Vecino de Ágreda. Herrero. Casado con María de Ruidíaz.

De más de 40 años de edad.

Confesó que toda su vida fue moro, porque cuando contaba con 10 ó 12 años le enseñó esta religión su madre.

56. RAMOS, Leonor de.

Vecina de Ágreda. Viuda de Juan Colato.

De 60 años de edad.

Confesó ser mora desde hacía cincuenta años, porque le enseñó la religión islámica una abuela suya.

57. REDAL, María del.

Vecina de Ágreda. Mujer de Lope Aquen, herrero.

De 36 años de edad.

Confesó ser mora desde hacía dieciocho años, porque ciertas personas le enseñaron la religión islámica.

Declaró haber realizado los ritos del Islam con su marido y con un hermano suyo.

58. RUIDÍAZ, María de.

Vecina de Ágreda. Mujer de Miguel Platero.

De 28 años de edad.

Confesó ser mora desde hacía catorce años, porque una tía suya le enseñó la religión islámica.

Como manifestaba dudas acerca de si era bueno o no seguir los ritos del Islam, otras dos personas la ratificaron en ellos hacía nueve años.

59. RUIZ, Damiana.

Vecina de Ágreda. Mujer de Alexandre Ozén, herrero.

De 32 años de edad.

Confesó ser mora desde hacía catorce años, porque le habían enseñado esta religión ciertas personas. 
60. RUIZ, Isabel

Vecina de Ágreda. "Moza» soltera.

De más de 25 años de edad.

Confesó ser mora desde hacía doce años, enseñada por cierta persona que nombró.

61. SALAZAR, Gracia de.

Vecina de Ágreda. Mujer de Leonís Platero, herrero.

De 27 años de edad.

Confesó ser mora desde hacía diez años, porque le había enseñado esta religión su marido.

62. SALAZAR, Miguel.

Vecino de Ágreda. Zapatero. Casado con Isabel de Camargo.

De 30 años de edad.

Confesó ser moro desde hacía dieciocho años, enseñado por su abuela y por una tía suya.

Declaró los nombres de algunas personas con las que practicaba la religión islámica.

Por miedo a la Inquisición, se ausentó en el reino de Aragón.

63. SALZEDA, María la, alias «la Florencia».

Vecina de Ágreda. Viuda de Juan Yron.

De 50 años de edad.

Confesó ser mora desde hacía treinta y cinco años, enseñada por sus padres.

Declaró los nombres de algunas personas con las que practicaba la religión islámica.

Por temor a la Inquisición se ausentó en el reino de Aragón, donde permaneció durante algún tiempo.

64. SANJUÁN, Lope.

Vecino de Ágreda. Zapatero. Casado con Gracia Ylela.

De 33 años de edad.

Confesó ser moro desde hacía quince años, enseñado por dos personas.

Por miedo a la Inquisición, se ausentó en el reino de Aragón por una temporada.

65. SEBASTIÁN, María.

Vecina de Ágreda. Viuda de Francisco Parra.

De 26 años de edad.

Confesó ser mora desde hacía quince años, porque le enseñó su madre.

66. SERRANA, Leonor la.

Vecina de Ágreda. Viuda de Juan de Turienzo, herrero.

De 40 años de edad.

Confesó ser mora desde hacía veintiséis años, enseñada por una tía suya. 
Declaró los nombres de algunas personas, con las que practicaba la religión islámica.

Por temor a la Inquisición, huyó al reino de Aragón durante algún tiempo.

67. SERRANO, Alexandre.

Vecino de Ágreda. Herrero y arcabucero.

De 28 años de edad.

Confesó ser moro desde hacía seis o siete años, enseñado por cierta persona que nombró.

Declaró los nombres de ciertas personas con las que practicaba la religión islámica.

Por temor a la Inquisición, durante algún tiempo estuvo ausente de Ágreda.

68. YANGUAS, María de.

Vecina de Ágreda. Mujer de Floristán Herrero.

De 28 años de edad.

Confesó ser mora desde hacía diez años, enseñada por su marido.

69. YLEL, Gabriel.

Vecino de Ágreda. Herrero.

De 64 años de edad. Padre de Gabriel y de Miguel Ylel.

Confesó ser moro desde hacía treinta y seis años, porque le había enseñado este religión cierta persona. Desde hacía cuatro años se había apartado de la misma.

70. YLEL, Gabriel.

Vecino de Ágreda. Herrero.

Hermano de Miguel Ylel, e hijo de Gabriel Ylel.

Confesó ser moro desde hacía dieciséis años, porque su padre le había enseñado esta religión. Por temor a la Inquisición, se ausentó en el reino de Aragón por algún tiempo.

71. YLEL, Miguel.

Vecino de Ágreda. Herrero.

De 33 años de edad. Hermano de Gabriel e hijo de Gabriel Ylel.

Confesó ser moro desde hacía dieciséis años, porque le había enseñado esta religión su padre.

Por miedo a la Inquisición, había estado durante algún tiempo en el reino de Aragón.

72. YLELA, Gracia la.

Vecina de Ágreda. Viuda de Juan de Arévalo del Cantón.

De 60 años de edad.

Confesó ser mora desde hacía cuarenta años, porque le enseñó esta religión cierta persona. 
Por miedo a la Inquisición, había estado en el reino de Aragón durante bastantes años.

73. YLELA, Gracia.

Vecina de Ágreda. Mujer de Lope San Juan, zapatero.

De 26 años de edad.

Confesó haber sido mora durante cuatro años, porque hacía seis años le enseñó esta religión su padre. Desde hacía dos años se había apartado del Islam.

74. YRON (nombre ilegible).

Vecino de Ágreda. Zapatero.

De 40 años de edad.

Confesó ser moro desde hacía veinticuatro años, porque con 15 ó 16 años le enseñó esta religión su padre.

Declaró los nombres de algunas personas con las que había practicado la religión islámica.

Por temor a la Inquisición, se ausentó en el reino de Aragón durante algún tiempo.

75. YRON, (nombre ilegible).

Vecino de Ágreda. Zapatero.

De 30 años de edad.

Confesó haber sido moro desde hacía quince años, enseñado por su padre cuando tenía 14 ó 15 años.

Por temor a la Inquisición, se ausentó en el reino de Aragón durante un tiempo. 